\title{
Nosotras nos hacemos a nosotras mismas: análisis psicosocial del proceso de construcción de la identidad lésbica y su relación con el espacio público y la vida en sociedad
}

\author{
Albanella Luena Chávez Turello \\ Universidad Privada Domingo Savio, Bolivia \\ albanella.chavez@upds.edu.bo
}

\section{Resumen}

El objetivo de este artículo es el análisis de las relaciones que se establecen entre el proceso de construcción de la identidad de las mujeres lesbianas con el espacio público como sitio de resignificación de su identidad personal y social, intentando integrar el intercambio que realizan de sus propios significados con los del medio, durante las etapas de crecimiento, autonombramiento y confrontación de normas sociales. La metodología empleada es el enfoque biográfico, con la técnica de los relatos de vida realizados a siete mujeres. Los resultados de la investigación apuntan a entender la relación entre la identidad, el reconocimiento social y su relación con el espacio público, como bases para la identificación como lesbianas de las mujeres participantes.

Palabras clave: identidad, sexualidad, género, lesbiana, homosexualidad. 


\title{
We make ourselves: psychosocial analysis of the process of building lesbian identity and its relationship with public space and life in society
}

\begin{abstract}
The aim of this article is the analysis of the links established between the process of constructing the identity of lesbian women with the public space as a site of resignification of their personal and social identity, trying to integrate the exchange they make of their own meanings with those of the environment, during the stages of growth, self-nomination and confrontation of social norms. The methodology is the biographical approach, with the technique of the life stories of seven women. The results of the research aim to understand the relationship between identity, social recognition and its relationship with the public space, as bases for identification as lesbians of the participating women.
\end{abstract}

Keywords: identity, sexuality, gender, lesbian, homosexuality.

Fecha de recepción: 10 de septiembre de 2019.

Fecha de aprobación: 29 de noviembre de 2019. 


\section{Introducción}

Las categorías 'mujer' y 'lesbiana' tienen muchas características y connotaciones que deben analizarse en relación directa con la vida en sociedad y el espacio público, como temas relacionados con el Enfoque de los Derechos Humanos y con los derechos sexuales y reproductivos. En particular, el proceso de construcción de la identidad de una mujer lesbiana implica el ejercicio de los derechos al reconocimiento de la sexualidad y a la expresión sexual.

Desde la perspectiva psicosocial, el eje que el presente artículo tomará como definitorio para el análisis será la identidad. Como mencionan Mejía y Pizarro (2011) la identidad es aquello que nos faculta a entender quiénes somos, mediante la progresiva construcción e intercambio con el medio de significados propios sobre distintos tópicos, tanto personales como sociales. Por su parte, Makaran plantea: “[...] la identidad se comprende como un proceso en curso, dinámico y evolutivo, y nunca una realidad dada e inmutable" (2017:113).

La identidad personal no se entiende como una cualidad inherente al ser humano, sino que es fruto de un proceso de articulación permanente entre la identificación y la diferenciación (Peña Hasbún, 2003). Esta se expresa a partir del sentido de pertenencia a un grupo determinado (Saldías, 2008), por lo que, al manifestarse de diferentes formas y dimensiones, queda inscrita en aquellas relaciones sociales que las personas entablan como configuración de su vida cotidiana.

En tal proceso, la dimensión social, a través de los procesos de aprendizaje del sujeto, es fundamental. En el caso de la sociedad cruceña, el análisis sobre las raíces de la cultura local, y su relación con los distintos fenómenos que le afectan son temas poco explorados en el ámbito académico y de investigación social (Villarroel, 2018), aunque en los últimos años han venido tomando fuerza, en especial la reflexión alrededor del tema de la identidad (Peña Claros, 2011, 2006; Boschetti, 2009; Saldías, 2008; Prado, 2008; Peña Hasbún, 2003).

Para aproximarnos a entender el constructo de la identidad que tienen las personas que nacieron y/o viven en Santa Cruz de la Sierra, tomamos la reflexión de Boschetti (2009), sobre que la misma se construye en referencia a qué se interpreta como hecho del pasado y qué se proyecta como deseo hacia el futuro. En coincidencia con ese análisis, apuntamos algunas ideas propuestas por Peña Hasbún (2003) y Peña Claros (2011). Ambas autoras coinciden en que la identidad 
cruceña se vincula de manera muy fuerte a la historia y tradiciones, como componentes de la memoria colectiva. Esta surge a partir de la "integración bio-social" (Carvalho, 1990, en Peña Hasbún, 2003) de tres poblaciones: españoles y nativos, desde la Colonia y, en la modernidad, los migrantes, tanto del interior como del exterior de Bolivia.

Prado (2008) presenta la migración como elemento de la historia reciente de la ciudad, que opera en la reconfiguración constante de la identidad cruceña puesto su explosivo crecimiento desde mediados de la década de los '70. A partir de 1976, año que se realiza el Censo Nacional de Población y Vivienda, se empiezan a registrar las oleadas migratorias desde los departamentos andinos y de los valles ${ }^{1}$, lo que empieza a fragmentar la sociedad y, por ello, la identidad cruceña unificada (Peña Claros, 2011).

En la actualidad según Ábrego (1994, en Peña Hasbún, 2003), la identidad cruceña se define a partir de su heterogeneidad, de acuerdo con la diversidad de identidades particulares de los habitantes que se conciben a sí mismos como "diferentes unos de otros". Al año 2011, tal diversidad se veía expresada en que el 51,8\% de los habitantes de Santa Cruz (Peña Claros, 2011) son provenientes de otros departamentos.

Podemos entender a la sociedad cruceña como sujeta a rupturas y fragmentaciones socioculturales en relación tanto a elementos socioeconómicos como de acuerdo con el gran porcentaje de población migrante. Esto puede verse en el estudio que realiza Peña Claros (2011) acerca la sociedad y la identidad cruceña, a partir de un análisis sociohistórico. La autora plantea que es una sociedad que se percibe a sí misma como desunida y con bastante estratificación, en función del: origen y herencia socioeconómica, etnia, nivel socioeconómico, ocupación, nivel de instrucción, género, edad, religión, etc.

A partir de allí, el punto de vista del presente análisis es el enfoque constructivista, según el cual, los componentes de las identidades cobijadas en el concepto de 'mujer' y 'cruceña' son referencias activas para delimitar la conciencia identitaria de cada persona que llega a identificarse y denominarse lesbiana en la sociedad cruceña

\footnotetext{
${ }^{1}$ El crecimiento poblacional de Santa Cruz ha sido exponencial, pasando de 254.682 habitantes (Ballivián, 1992) en el año 1976, a 1.454.539 (Concejo Municipal de Santa Cruz de la Sierra), con una población de 2.039. 000 en toda el área metropolitana (municipios de Santa Cruz de la Sierra, Cotoca, Porongo, La Guardia, El Torno y Warnes).
} 
La justificación para la presente investigación se plantea desde la necesidad de marcos de entendimiento para analizar los componentes de la identidad como tópico primordial al momento de entender la propia persona. Al mismo tiempo, tales esquemas son necesarios para los caminos particulares que toman los diversos procesos de construcción identitaria de las diversas orientaciones sexuales, en relación con el estigma y discriminación que supone su afirmación pública (Ministerio de Comunicación del Estado Plurinacional de Bolivia, 2018).

\section{Método}

La metodología cualitativa del presente estudio se define como exploratoria, desde el enfoque biográfico con la técnica de los relatos de vida. Los relatos de vida son la tarea analítica que se hace sobre el relato, escrito $\mathrm{u}$ oral, que realiza una persona de su historia de vida (Cornejo, Mendoza y Rojas, 2008).

Esta técnica fue utilizada tanto para ser la guía de las entrevistas, como para estructurar los relatos contenidos en ellas, permitiendo así la interpretación de las narraciones y el desarrollo de cada una de las etapas del proceso de investigación: recolección, análisis e interpretación de datos. A su vez, la metodología de análisis de los datos resultantes es el propuesto por Taylor y Bodgan (1984:159). Se compone de las siguientes etapas:

1. El descubrimiento e identificación de temas: en esta etapa se llevó a cabo el desarrollo de conceptos y proposiciones.

2. La codificación y categorización de la información recogida: se llevaron a cabo sucesivos procesos de reunión y análisis de datos extraídos de las revisiones bibliográficas de la literatura pertinente y de las entrevistas realizadas a las mujeres participantes.

3. La relativización de los descubrimientos, como etapa centrada en la comprensión de los relatos, por medio de la interpretación e interrelación de la información recogida.

Se contó con la participación de 7 mujeres, a las que se les realizó un total de 13 entrevistas en profundidad sobre su historia de vida. El tipo de muestreo fue no probabilístico y dirigido, de 
selección informal (Hernández, Fernández, \& Baptista, 2016), no obstante, aquellos criterios que fueron establecidos por el estudio, se ha optado por la modalidad específica por conveniencia o de sujetos voluntarios.

Todas las mujeres entrevistadas, al momento de participar en la investigación, vivían en la ciudad de Santa Cruz de la Sierra (Bolivia), con edades comprendidas entre los 17 y los 32 años, de nivel socioeconómico medio y cinco de ellas nacidas en ciudades del interior del país. Fueron elegidas de acuerdo con las características de su historia, edad y estilo de vida, con una etapa previa de toma de confianza y familiaridad de aproximadamente ocho meses.

De forma complementaria se usó la técnica de la observación participante en reuniones y eventos de socialización de mujeres lesbianas y bisexuales. Es un método de recolección de datos propuesto por el enfoque etnográfico (Sandoval, 2002) y consiste en el abordaje participativo, abierto, flexible y acumulativo de las dinámicas del contexto durante el proceso de investigación.

La totalidad del proceso investigativo se logró de manera consecutiva, a razón de la confianza y los vínculos establecidos con las entrevistadas, a través de las reuniones y espacios compartidos en los que se las acompañó.

\section{Resultados}

Como producto de la investigación que se llevó a cabo al respecto del proceso de construcción de la identidad lésbica, fue posible elaborar una matriz de once categorías teórico-temáticas ${ }^{2}$, a partir de los códigos obtenidos de las entrevistas. No obstante, al centrarnos en el análisis de las relaciones de las mujeres lesbianas con el espacio púbico, solo serán incluidas las tres categorías que coinciden con ese objetivo, descritas y analizadas a continuación.

\section{a) Niñez y adolescencia}

"Yo siempre era el papá (...) Vos vas a ser mi hija y vos vas a hacer esto (...).

\footnotetext{
${ }^{2}$ Las categorías restantes son: El papel que juega la familia, la actitud mostrada por los profesionales de la psicología, el ambiente, las relaciones de pareja lésbica, los roles de género masculinos o femeninos, el valor que es otorgado a la virginidad, el significado del ser mujer y del ser lesbiana.
} 
Yo siempre era la figura dominante".

Paola

La infancia o niñez de las mujeres es una etapa donde empieza a tomar forma el deber ser, como modo por el cual son asumidas las obligaciones y estereotipos de género. Para las mujeres entrevistadas, la atribución de características indicadas como femeninas o masculinas significó la obligatoriedad del uso de determinados juguetes, prendas de vestir y una forma específica de hacer uso del espacio público diferente a la de los chicos. Como muestra de esto, podemos leer a Beatriz:

[...] a los 7, 8 años me obligaban a ponerme vestido y yo lloraba y le decía que no quería usar eso y mi madre me echaba huasca ${ }^{3}$, salía de la iglesia y volaba a mi casa porque no era muy lejos y me cambiaba a short y polera.

Todas las entrevistadas pasaron en esta etapa por un periodo de confusión a raíz de la poca información y apertura por parte de sus padres y referentes de confianza. De ese modo, varias de ellas relatan haberse sentido más identificadas con sus referentes masculinos que con el modelo social de feminidad. Como ejemplo tenemos los relatos de Carolina y luego Paola en cuanto a su relación con los otros niños y niñas:

[no jugaba] el juego de mamá y papá, [donde uno de ellos] iba a ser papá y yo mamá y yo no quería pues especialmente si yo estaba con la peladita ${ }^{4}$ esa; siempre yo paraba peleando con los pelados, después eran amigos, no otra cosa.

Así que mis compañeros [me decían] “jasí que vos sos gay!” yo paraba de pelo corto, parecía hombre y desde ahí me quedé con 'Pablo' en el colegio.

\footnotetext{
${ }^{3}$ Pegar o azotar con guasca o instrumento de castigo.

${ }^{4}$ Niña, chica.
} 
b) Procesos de 'Percepción de la diferencia', 'autonombramiento 'y 'salida del closet'

“[...] según yo, si amas a una persona quieres que sea feliz, ¿no?

No entendía por qué querían tanto que sea heterosexual."

Diana

Para las mujeres entrevistadas, al no existir información al respecto de qué es orientación afectivo-sexual lésbica, atravesaron por periodos de confusión respecto al porqué de sus impulsos y/o conductas. Según sus testimonios, desde niñas aprendieron que solamente los hombres pueden gustar de las mujeres y, por ende, las lesbianas se caracterizan por ser masculinas; de esa manera, llegaron a asociar su atracción por otras mujeres con el modelo masculino heterosexual.

Beatriz: No sé, yo lo hallaba... por ejemplo no sé, como en ese sentido mi mamá y mi papá nunca me dijeron que el hombre era con la mujer ni nada entonces ellos se metían o sea no [...] O sea, digamos, sabía que me gustaban, pero nunca quise averiguar, digamos, el porqué. Cuando me llegó esa duda tenía unos trece años, le dice mi tía que estaba charlando con mi mamá, yo estaba por ahí y le dice "imagínese que Maruja, allá vive, con una pelada. Dice que es su hijo. Dónde puej, se ha visto eso".

Carolina: No, no sabía, no quería buscar en Google ni nada. O sea, no sabía si eso era una relación lesbiana ni nada. Tenía noción que existía, pero no sabía si lo que yo estaba viviendo era eso.

Diana: Y cuando era adolescente eso me hacía sentir muy mal [...] mi mamá las envidiaba a todas las chicas que eran femeninas, delgadas, bonitas, que entraban en su sueño.

c) Vida en sociedad

"[...] si quiero a mi pareja, [...] no podemos demostrarlo como todas las personas y salir libremente como cualquier pareja, porque existen los lugares que no podemos".

Beatriz

Todas las entrevistadas relataron episodios en los cuales tuvieron que enfrentar situaciones de homofobia y rechazo social, sustentadas en la creencia acerca la superioridad de la heterosexualidad respecto a la homosexualidad. El resultado fue que, al denostar la orientación sexual lésbica, varias de ellas decidieron renunciar a las demostraciones explícitas de afecto o amor hacia otra mujer. 
Carolina: Antes era mejor, creo. Antes podías pasar con una chica y agarrarla de la mano, digamos. Y la gente no decía nada. Ahora, pasas con una chica agarrada de la mano y la gente [susurra] "es lesbiana", cuando no estaba tan salido a la luz la gente lo veía como algo normal.

Paola: [...] Siempre, de los pelados "ay, esa es lesbiana, yo la voy a hacer mujer", es su pensamiento, de todos $[\ldots]$

En varios casos referidos, las mujeres narran la manera cómo tal conducta explícita (besos, abrazos, tomarse de la mano, etc.) es entendida socialmente como 'provocación'. En estas situaciones el mecanismo de reacción de la sociedad es invertir los papeles, resultando que los agresores no son los que reaccionan violentamente ante las mujeres que demuestran su amor públicamente, sino que son estas mujeres las que "agreden" a los transeúntes con sus acciones.

Otro punto de convergencia entre varias de las mujeres entrevistadas fue el sentido de libertad e independencia al que se puede llegar. Como dicen Carolina y María:

[...] Voy a morir siendo así, tampoco voy a casarme tener hijos para complacer a la sociedad. Pero en lo que yo pueda trataré de hacer mi felicidad con la persona que yo quiera y es una mujer.

Como piensa la sociedad, me vale. Todo me vale. Como digo "vos no vivís de la gente", si andas con tu pareja en la calle, a vos que te valga un pito si la agarrás de la mano, aunque la gente te apunte con el dedo, qué vas a hacer, nada, eso depende de uno, de lo que es al final [...]

\section{Discusión}

a) Niñez y adolescencia

"Lo único que yo me preguntaba era ¿por qué? ¿Por qué me gustaba verlas a mis primas? Y no sabía si decirle a mi papá lo que me pasaba y preferí callarme". María

En palabras de Mayobre (2007), la internalización de la asimetría entre hombres y mujeres es parte del proceso de formación de la identidad personal, adaptándose el comportamiento y acciones en ese sentido.

En relación con nuestro tema, las niñas aprenden a ser niñas en relación con la educación que reciben y las dinámicas familiares que observan y que, en muchos casos, se basan en los presupuestos binarios: la superioridad, cultura y racionalidad asociada al género masculino, con 
la inferioridad, naturaleza/cuerpo e irracionalidad, asociadas al género femenino. Por ser que la infancia se desarrolla en ese entendido, se plantea muy marcada la característica binaria de varios de sus componentes: la ropa, los juguetes y el espacio de juegos. Vemos, en esa línea, el testimonio de Carolina:

[...] yo tenía un tractor de madera, que era changuita ${ }^{5}$, no sé cuántos años tenía, que yo no lo soltaba y corría por todo el patio [...]. Mi hermana [...] quería que yo también juegue con muñecas, dentro de la casa y yo jugaba con el bendito tractor. No sé cuánto tiempo estuve ahí, creo que fue más de un año que mi abuela, con mi madre y mi tía me lo quitaron el tractor, me lo botaron y creo que lo enterraron, estuve como dos meses llorando por mi tractor de madera. Dijeron que eso no es para niñas, que mi juego debía ser sólo en casa.

Es así que varias de las mujeres rechazaron la obligatoriedad de los juegos con muñecas, pues preferían los camiones, pelotas, etc., de modo que, según el relato de las mujeres, todas las que les regalaban o compraban sus padres quedaban guardadas y sin uso.

En otra experiencia tenemos el relato de Paola. Ella refiere que nunca se sintió obligada a vestirse ni jugar como 'mujercita', a pesar de que su madre peleaba con su padre para que usara vestidos y se vistiera de forma más femenina. A esto, Paola declara haberse sentido siempre más cómoda con la ropa de niño, refiriéndose a los overoles y botines, pues, como nos dice ella: "los vestidos no dejan correr ni saltar."

Volviendo a las palabras de Mayobre (2007) en relación con los planteamientos de Puerta Sánchez \& González Barea (2015), tanto la vestimenta como la elección de juegos, juguetes y roles para desarrollarlos, están relacionados con las atribuciones de género. En este sentido, es posible analizar el papel que tomaba Paola en los juegos que compartía con sus primas (la casita), donde ella siempre era el papá dominante. Tal juego se caracteriza por tener papeles definidos para cada participante (el papá y la mamá), además de características conductuales y lugares de desenvolvimiento definidos (el papá ordena y se maneja en toda la casa, la mamá obedece y se restringe a ciertos espacios, en relación con las tareas domésticas).

En el mismo juego, Beatriz, manifiesta que no le gustaba por no querer desempeñar el papel asignado a las niñas (la mamá), y frecuentemente intentar ocupar el lugar dominante frente a las

\footnotetext{
${ }^{5}$ Niña.
} 
demás niñas "[...] especialmente si yo estaba con la peladita esa; siempre yo paraba peleando con los pelados, quería ser el papá y ellos después eran amigos, no otra cosa."

De lo anterior resalta un tema importante, que ya fue nombrado como uno de los resultados de la investigación: la confusión que pueden sentir las mujeres lesbianas acerca de quiénes pueden tomar como modelos de conducta en su proceso de aprendizaje y desarrollo de la personalidad.

Le Garrec (1989), apoyada por Juliano (2002) explica que los modelos hacen las veces de referentes en cuanto a los roles que tomar y las actitudes que asumir ante las demás personas y hacia sí mismas. Para las mujeres lesbianas entrevistadas, los modelos de conducta fueron también modelos de género; entre ellos, están mayormente actrices, actores y cantantes estadounidenses o europeos, tanto gays, como lesbianas y bisexuales.

La confusión, desarrolla Le Garrec, se entiende que exista pues, en muchos casos, las mujeres lesbianas en su proceso de autodescubrimiento, "no pueden reconocerse en ninguno de los dos modelos [primarios]" (1989:79) que son la madre y el padre: aunque la madre es también mujer, es la esposa del padre; el padre, con el que, a pesar de encontrar puntos en común, es hombre y esposo de la madre, además que ambos son heterosexuales.

De tal modo, al estar el modelo de 'mujer', ciertamente estereotipado, tan lejano a su conducta, gustos y emociones, las mujeres efectuaron una conexión con el canon masculino, negándose en sí misma la condición de mujer.

Este rechazo se funda en que las mujeres se encontraron ajenas, diferentes a los referentes de género que el modelo de mujer cruceña que se sustenta. Para entenderlo, tomamos el aporte del Sanabria (2016) que destaca el valor otorgado a los roles de madre y esposa, de manera conjunta al realce que se le da a la belleza física y al cuerpo estéticamente bello, proporcionado y exuberante. La cultura camba ${ }^{6}$ pone mucho énfasis en los roles de género, todo esto como "mandatos jerárquicos" (Sanabria, 2016:101), desde el ideal sustentado para hombres y mujeres: la pareja heterosexual, que se organiza según el modelo del hombre como proveedor y, la mujer a cargo del hogar y el cuidado de los hijos (Prado et. al., 2005 en Peña \& Boschetti, 2008).

\footnotetext{
${ }^{6}$ Representación simbólica de la cultura de los habitantes de las Tierras Bajas (zona tropical y selvática), que se contrapone al "término "colla" [que] semánticamente proviene del nombre que se les asignó a los pobladores del incaico Qullasuyu" (Makran, 2017:114), habitantes de la zona andina y valluna.
} 
Si bien varios autores coinciden en que algunas características son del discurso hegemónico (Peña Claros, 2011; Peña \& Boschetti, 2008; Peña Hasbún, 2003), conectado al poder económico y político, no es posible obviar el impacto que este tiene en la organización cultural y social de todos los niveles de la sociedad, al depender de ellos los medios de comunicación masiva y, por ende, muchas percepciones de la sociedad en general. Como expresa manifiesta Prado et al. (2005:105, en Peña \& Boschetti, 2008:164): "la sociedad y los medios de comunicación promueven una imagen estereotipada de los roles de género".

En ese sentido, resaltamos el análisis de Bergholdt (1999, en Peña \& Boschetti, 2008) acerca del concepto cruceño de mujer. Para el autor, una característica cultural es el valor que la cultura le otorga a la belleza, como se pone de manifiesto en la relevancia de las reinas de belleza y modelos, que tienen un papel muy importante en las dos fiestas principales de la cultura local: la reina del y la reina de la Feria Internacional Expocruz, que se ocupa de exponer y promocionar a las principales empresas e industrias del ámbito agropecuario de la región boliviana y sudamericana.

De acuerdo a su relación con la belleza como condicionante de género hacia las mujeres, Peña \& Boschetti la retratan así:

La Feria no sólo es una 'ventana al mundo' para mostrar el poderío económico de la región del Oriente, sino también un símbolo de distinción étnica y de clase. Allí se observan como en ningún otro lugar y ocasión las figuras paradigmáticas de la sociedad cruceña: las bellas mujeres y los progresistas empresarios. Las empresas seleccionan y disputan desde tiempo antes a las 'mejores' 'azafatas'7 para sus stands. Los periódicos locales las entrevistan antes, durante y después de la Feria, y su participación en uno u otro stand (para una u otra empresa) les otorga jerarquía en sus carreras. Santa Cruz 'muestra' durante la Feria no sólo su producción agropecuaria e industrial sino también a sus mujeres (jóvenes, alegres y dotadas de una belleza acorde a los parámetros occidentalizados). El broche de oro en este sentido es la elección de la azafata más bella, concurso organizado por el diario El Deber (2008:190-191).

Como dijimos anteriormente, este es el marco que nos aproxima al modelo de mujer que se sustenta en la cultura de Santa Cruz de la Sierra. Las participantes, en varios casos, renegaron o no se sentían representadas por la categoría de mujer, por ser entendido este concepto como

\footnotetext{
${ }^{7}$ Se las entiende como promotoras para las empresas y productos. En su mayoría son modelos y/o reinas de belleza.
} 
heterosexual por definición y con normas genéricas sobre la vestimenta, arreglo personal, formas del cuerpo, etc. (Lacombe, 2013; Sánchez, Gil, Farah \& Tapia, 2016) tan distintas a los propios.

En relación con todo lo anterior, hallamos el relato de Carolina: «todo el tiempo me decían [mi familia y amigos] que yo era una marimacha por mi ropa, mi cabello, mi cuerpo y todo lo demás. Entre cuatro mujeres, la única media hombre salí yo». Es decir, dado que ella no se adaptaba al canon de género establecido, sus personas cercanas no la catalogaban como mujer en todo el sentido de la palabra.

Para entender lo anterior, leemos a Guerra (2011). La autora plantea que, al ser la construcción de la sexualidad creada mayormente en espacios cerrados: la casa, la mujer o la familia, se cancela o dificulta la posibilidad de conexiones de soporte con la comunidad primaria y el acceso a los elementos de la identidad desde la autodefinición, pues debe moverse entre las ideas prescritas, en forma de prejuicios y la noción de anormalidad.

\section{b) Procesos de autopercepción, autonombramiento y salida del closet}

"Sabía que me gustaban, pero nunca quise averiguar por qué"

Beatriz

Aunque los pasos de la autopercepción, autonombramiento y 'salida del closet' pueden darse de manera consecutiva o más espaciada y pueden estar presentes en varias etapas de la vida, por su importancia, se extrae del conjunto para su mejor análisis y comprensión.

El proceso de autopercepción comprende la fase de reflexión y cuestionamiento de los elementos con los que la persona se identifica, incluidas su sexualidad y forma de vida (Silva Luévanos, 2018; Platero \& Fernández, s.f.). Está psicológicamente caracterizado por ser un periodo de malestar y conflicto originados por la presión social y cultural, especialmente en aquellas personas que no se adscriben a la heteronormatividad ${ }^{8}$.

\footnotetext{
${ }^{8}$ La norma heterosexual o heteronormatividad es definida como "el conjunto de prácticas culturales, legales e institucionales que mantienen el enfoque normativo de la existencia de dos géneros, en correspondencia con el sexo biológico, por lo que la atracción sexual entre estos géneros es lo natural o lo socialmente aceptable" (Roque Guerra, 2018:1-2)
} 
Como vimos antes, para las mujeres lesbianas este paso viene de un periodo de confusión sobre su identidad de género, sexual, etc., basado en que se niega el conocimiento sobre sí mismas, su cuerpo y/o se manejan estereotipos y prejuicios sobre ambos temas. Además, esto coincide con la poca información con la que cuenta la población cruceña en general sobre la homosexualidad, sexo, género, etc. (Villarroel, 2008).

Lo anterior puede verse en la experiencia de Natalia: «Yo no sabía que había mujeres que se gustaban con mujeres, pensaba que era algo malo, pero a mí me gustaba y mientras que nadie se entere, yo estaba callada». Los elementos que fueron persistentes en todo su proceso fueron: la duda, el silencio y la confusión, el temor por la reprobación y el estigma que perciben sobre sí mismas.

Por otro lado, la claridad sobre este punto nos la brinda Beatriz:

Cuando me llegó esa duda tenía unos trece años, le dice mi tía que estaba charlando con mi mamá, yo estaba por ahí y le dice "imagínese que Maruja, allá vive, con una pelada. Dice que es su hijo. Dónde puej, se ha visto eso Cómo, yo que su madre...". O sea, mi tía era de las que pensaba que haciéndolo violar a uno, uno se iba a moderar. Y yo quedé pensando "Pucha, será que, o sea uno va a llegar a pensar, si se supone que uno no puede hacer hijos". No me llegó la duda de que me gustaran las mujeres, sino me llegó la duda de que, si alguna vez me llegara a pasar eso, qué pasaría. Porque después, sabía que me gustaban, o sea bueno, sí era raro que no me gusten los chicos, aunque para jugar, no para estar con ellos.

Como puede verse, los contenidos esenciales del testimonio se inclinan por los puntos vistos anteriormente: la duda por la falta de conocimiento del tema, las creencias heteronormativas manejadas por la familia y de igual forma por las personas de su entorno; el efecto que tiene la educación basada en el silencio hacia lo relacionado con la sexualidad; la percepción de ser rara o diferente y la referida al concepto sobre que a toda mujer debe atraerle el hombre.

En este sentido, las reflexiones sobre las bases de la educación citan varias contribuciones acerca de la norma heterosexual o heterosexualidad obligatoria, como su pilar (Preciado, 2010; Rich, 2009; Mogrovejo, 2008; Sanfeliu, 2007; Alfarache, 2005). Es así que, según estos análisis, la heterosexualidad se entiende como un presupuesto dado por automático en la educación de las mujeres, que se funda en una clara oposición entre quién es una mujer femenina y heterosexual, y quién no lo es (Sánchez, Gil, Farah \& Tapia, 2016). La norma heterosexual se halla inserta en las 
enseñanzas que otorgan la escuela y la familia nuclear o tradicional, además de los contenidos que reciben de los medios de comunicación y de su entorno social.

De acuerdo con los relatos de las mujeres entrevistadas, la educación con base en la norma heterosexual tuvo un significado importante en el proceso de construcción de la identidad por el que transitaron pues les permitió entenderse a sí mismas como no-heterosexuales. A partir de allí, las mujeres narran que les fue posible autonombrarse como lesbianas. Castañeda (2001) define este momento como aquel donde la mujer puede nombrar qué es lo que siente. De acuerdo a la experiencia de las mujeres entrevistadas, Herrera (2007) apunta como parte indispensable del proceso de construcción de la identidad lésbica el hecho de tener conocimiento del concepto de lesbiana, sus características, qué implica, etc. Para poder identificarse con una categoría es fundamental poseer información, tener la capacidad de nombrarla.

Para el proceso de autonombramiento es preciso que se sepa que existen las mujeres lesbianas y además que la mujer pueda identificarse con el concepto y asumirlo para sí. Esto lo vemos en la experiencia de Carolina:

[...] conocí a un par de amigas, me las presentaron, que una era una rockera, una bisexual loca que, poco más, ella me explicó: "esto es amarillo, esto es verde y vos sos así", 18 años creo que tenía. Me dice “¿Tenés pareja?”, "Pareja, no sé”, “¿Te gustan las mujeres, no ve?”, "Sí”, "No te gustan los hombres, ¿no?”, "No”, “¿Entonces te gustan las chicas!”, “Ajá”, “¡Entonces sos una lesbiana! Por qué no te gustan los hombres ¿no?

Es decir, al momento que tomaron contacto con la categoría y su concepto, lo enlazaron con su vivencia y pudieron adoptarlo para sí. En las palabras de Paola: “[...] me destapé, como era una chica encerrada, me recontradestapé, yo era la voz de mando, el líder del grupo, imagínate semejante cambio, $[\ldots]$ me cambió bastante. Terminé de confirmarme a mí misma".

No obstante, los pasos que se dan en el sentido de la ratificación de la duda no son siempre lineales, pues, como dice Le Garrec (1989), la conciencia de la propia homosexualidad puede no significar su aceptación.

En todo caso, como explica Castañeda (2001), el autoreconocimiento es progresivo, al implicar desde la verificación de la orientación sexual por medio de una experiencia sexual, hasta la superación de un proceso de duelo por la heterosexualidad perdida, pudiendo ocurrir durante o 
después de la etapa de exploración. Significa despedirse de la heterosexualidad que, como forma de vida, ha sido inculcada y es alimentada por la vida en sociedad. Como expone Castañeda (2001), al terminar este periodo, muchas veces recién puede darse la aceptación de la orientación sexual lésbica.

La experiencia de todas las participantes fue haber tenido que decir la verdad acerca de su orientación afectivo-sexual de manera obligada $y$, en primer lugar, a su familia. Dichas narraciones tienen como eje transversal que fueron las normas, tanto implícitas como explícitas, dentro de las familias, las que definieron las reacciones a la noticia. En el caso de Beatriz, ella considera que muchos temas eran callados por ser tabús $\mathrm{y}$, por eso, nunca hablaron sobre su orientación sexual a pesar de que la madre decía sobre ella «(...) vive como vive porque es feliz y qué puedo hacer, pero no creo, es que a ella solo le gusta compartir con sus amigas».

Tanto en ese caso como en el de Diana y Carolina, el silencio fue la regla hacia la noticia y este implica algo más que sólo no hablar o tocar el tema, pues es tomado como una prohibición hacia la forma de vivir la afectividad, y que actúa como invalidación permanente.

Como tema genérico, para Rich (1983, en Alfarache, 2005) el silencio que pesa como aprendizaje del ser-mujer es parte fundamental de las vidas de muchas mujeres lesbianas.

Por otro lado, en el caso de Diana, ese silencio tomó la forma de reproche velado, expresando la madre 'envidia' por las adolescentes que «eran femeninas, delgadas, bonitas, que entraban en su sueño». A su vez, en el caso de Carolina, el paso de salir del clóset se dio de forma brusca por una comunicación de la escuela a la madre pidiendo que la lleve a consulta psicológica, tomándoselo de forma muy negativa, con llanto y reprimendas.

En ambos casos vemos lo que Castañeda (2001) aclara, que el hecho de salir del clóset no puede pensarse como un proceso solamente individual, sino como se ha visto, es de carácter familiar y social. Dentro de la familia se ponen en cuestión temas que pueden originar la culpabilización, el enfrentamiento entre los miembros, etc. Hacia afuera, además de que una familia es el reflejo de la sociedad donde vive y lleva consigo valores morales, en muchos casos homofóbicos, misóginos y machistas (Quiles, 2001), todos los integrantes deben decidir qué explicación dar 
acerca de la forma particular de vida de la mujer lesbiana (Le Garrec, 1989), en el sentido de pareja o amistades.

Hasta aquí, el proceso de construcción de la identidad ha sido visto en su mayoría en espacios circunscritos al ámbito familiar y personal de las mujeres. Una vez que ellas fueron aclarando su duda persistente acerca de sí mismas y luego tomaron contacto con la categoría lesbiana, pudieron iniciar el establecimiento de vínculos de soporte con otras mujeres y/o personas noheterosexuales en entornos con dinámicas particulares para la sociabilidad homosexual, en especial en los lugares 'de ambiente'. En la ciudad de Santa Cruz de la Sierra este entorno lo componen varias discotecas, boliches y lugares de encuentro, a los que concurren mujeres lesbianas, hombres gays, mujeres y hombres bisexuales, y mujeres y hombres trans.

El 'ambiente', explica Herrera (2007), permite los procesos de recopilación de información para la estructuración de categorías sociales. Es decir, como comenta un grupo de mujeres lesbianas a las que se les preguntó por qué van a lugares de 'ambiente': «ahí uno va a ligar», «puedo conocer mujeres como yo, ver si alguna me gusta y lanzarme, sin tener que estar viendo si alguien me mira, me observa, me juzga», «son los únicos lugares donde nos podemos ver entre nosotros y hacer las cosas sin que los demás nos juzguen».

Como explica Mosher (2001, en Herrera, 2007), los lazos de amistad entre personas con características identitarias similares constituyen un entorno de validación, pues mediante la participación activa en la cultura LGBT se asimilan referentes y se consolidan redes de apoyo alternas a la familia, lo cual proporciona sentimientos de valoración positiva. Si partimos de esa idea, explica Lacombe (2013) estos locales nocturnos tienen la suerte de legitimar o deslegitimar las distintas expresiones de género que los frecuentan.

Son espacios que otorgan la libertad y el soporte social necesario para poder expresar abiertamente la identidad, por lo que se puede entender el efecto positivo que tiene en la autoestima y autovalidación, además de la conformación de redes de apoyo (Barrientos y Cárdenas, 2013). Un componente importante de este proceso son también las redes sociales del entorno virtual pues a los elementos antes nombrados debe sumarse el rol que tienen estas plataformas en la comunicación (Garay Cruz, 2008). 
En el proceso que las mujeres siguieron, su toma de contacto con el espacio público ocurrió a partir de su encuentro con otras personas desde su expresión identitaria, con la ocupación de espacios físicos y afectivos. Esto se vio confirmado por el proceso que cada una vivió para salir del clóset o asumir la identidad o definición como lesbiana ante los demás (amigos, familia, comunidad).

En ese sentido, como aportan Aruquipa, Estenssoro \& Vargas (2012) en concordancia con Rabbia \& Iosa (2011) desde una mirada centrada en los colectivos LGBT ${ }^{9}$, la importancia del espacio público es determinante al permitir la expresión y visibilización de expresiones divergentes de género, afectividad y sexualidad, así como la articulación y organización de agrupaciones con cuestionamientos y demandas políticas de reforma o trasformación.

\section{c) Vida en sociedad}

“[...] si quiero a mi pareja, (...) no podemos demostrarlo como todas las personas y salir libremente como cualquier pareja, porque existen los lugares que no podemos".

Beatriz

Para entender las palabras de Beatriz, acudimos a Le Garrec que entiende el hecho que narra como una "frustración del acto de ternura" (1989:70), diciendo que, ante la incomodidad o rechazo que demuestran otras personas al ver actos de cariño entre mujeres, ellas reprimen su comportamiento o cohíben sus muestras de cariño o amor hacia otras mujeres. Es decir, las entrevistadas señalan que deducen la existencia de un código de conducta tácito en la sociedad sobre el comportamiento que deben tener las mujeres entre si y que este prohíbe las muestras explicitas de afecto; de ese modo, el rechazo es la manera como se penaliza a quienes no siguen tal acuerdo implícito y esa es la razón para que esta regla también sea la que norma su comportamiento.

Las participantes coinciden en que estas normas, si bien no tienen fundamento escrito, están basadas en las costumbres y están arraigadas en la mentalidad cruceña, lo que legitima y fortalece

\footnotetext{
${ }^{9}$ Siglas referidas a las poblaciones de la diversidad sexual y genérica: lesbianas, gays, bisexuales, travestis, transgénero, transformistas y transexuales.
} 
su accionar. De parte de la población heterosexual, toma muchas veces la forma de la homofobia, como rechazo y miedo irracional hacia las personas homosexuales (Castañeda, 2001).

Todas las entrevistadas han relatado episodios en los cuales han tenido que afrontar episodios de homofobia que, tomándola como fenómeno cultural (Aruquipa, Estenssoro y Vargas, 2012), en la sociedad cruceña que está sustentada por el gran valor que le otorga a la familia y, con ella, los roles tradicionales de género, en desmedro de quiénes no se guíen por ellos (madres solteras, personas transexuales, transgénero, mujeres masculinas, etc.).

Desde los relatos de Fabiola y María, sobre el colegio o su familia que las enviaba al psicólogo por estar enfermas, pasando por la reacción que los compañeros y profesores de Diana tuvieron hacia ella al enterarse que es lesbiana, hasta el relato que hace Carolina sobre las acciones del personal de un medio de comunicación:

Diana: No lo tomaron muy [bien], fue un poco "ah, estás enferma, hay que llevarte a un psicólogo".

Carolina: Cuando estaba con mi primera pareja, íbamos caminando de la mano y en ese tiempo estaba de moda [el canal de televisión] Megavisión. Estaban con sus cámaras y nos encerraron entre dos autos en la acera, que éramos dos lesbianas para el informativo, que les voy a enseñar qué es un hombre y vos sabes todas las guarradas que dicen. [...] Se paró el chofer y el otro se bajó corriendo con la cámara. Eso me traumo, era pelada de 20 años más o menos "que hay que enseñarles que es un hombre, que se hacen entre ustedes" todo eso. Nunca más quise agarrar de la mano a una chica, ni por la plaza. Tengo miedo que venga un tipo y me diga "i¿Qué hacés vos con una mujer?!”.

El punto en común de todos los relatos es la vivencia negativa que las participantes tuvieron hacia las actitudes homofóbicas, basadas en información estereotipada, incorrecta e incompleta (Villarroel, 2018) de otras personas y que, a razón de evitar malas experiencias de manera repetida, prefirieron condicionar su conducta a lo 'socialmente permitido'. En palabras de Beatriz:

[...] tenés ciertas condiciones que tenés que cumplir como por ejemplo no salir a la calle y gritarlo, o si vas a una fiesta no agarrar a tu pareja de la mano y besarla. Es bastante grave y es como una enfermedad. Hay ciertos roles y si los cumplís tendrás una vida tranquila sin que nadie te joda $[\ldots]$ vos sos una sola y el mundo es algo más grande que vos. 
Por otro lado, puede entenderse que también hayan asumido culpa sobre su conducta y de esa forma, la situación se invierte, pues «los agresores no son los transeúntes que reaccionan violentamente ante dos mujeres que se demuestran su amor en público, sino esas mismas mujeres que actúan como provocadoras e infligen, imponen, un espectáculo que resulta insoportable al medio que las rodea» (Le Garrec, 1989: 73). Como manifiesta Carolina:

Lo que pasa es que vivís con cierto modelo y como sos diferente, en vez de cambiarlo te unís al mismo modelo, no sé por qué. Es algo que se contradice, renegás de eso, pero terminas uniéndote a eso, no sé por qué.

\section{Conclusiones}

Creemos necesario recordar que, si bien el objetivo planteado para este artículo fue el análisis del vínculo entre el proceso de construcción de la identidad de las mujeres lesbianas con el espacio público como elemento imprescindible para la resignificación de su identidad personal y social desde tres categorías teórico-temáticas, la investigación de la que se extrae el análisis tiene una estructura de once categorías. A ese respecto, vemos conveniente realizar una síntesis de las conclusiones obtenidas en dicha investigación base, lo que nos permitirá una visión más amplia para su consideración. Pasamos a enumerarlas (Chávez Turello, 2019):

1. Las mujeres lesbianas de Santa Cruz de la Sierra construyen su identidad lésbica atravesando por múltiples etapas, en las cuales están involucradas ellas mismas, sus familias y medio social.

2. En todo el proceso van construyendo al mismo tiempo su identidad de género, a través de todas las atribuciones socialmente establecidas a la mujer que les son transmitidas en su vivencia diaria.

3. A raíz de esto, deben enfrentar e intentar superar experiencias negativas, rechazos y discriminación, al mismo tiempo que aprenden las formas de entablar lazos afectivos y de soporte con otras personas, y establecen relaciones afectivas con otras mujeres.

4. Como resultado de todo el proceso, las mujeres participantes pudieron-asumir y aceptar su orientación afectivo-sexual, siendo favorecidas su autoestima, relaciones interpersonales y de pareja, etc. 
Desde esos puntos como marco identitario para las mujeres lesbianas, las participantes dan cuenta de las vivencias negativas que suponen sus intercambios con problemáticas sociales y culturales asociadas a la homosexualidad, como son, desde el punto de vista del contexto: la imposición de los roles de género, la homofobia, la violencia de género y la dificultad en el acceso a la información. Aspectos que se traducen en temor y autocensura.

$\mathrm{Su}$ forma de desarrollarse haciendo uso del espacio público es primordial desde los ámbitos social e individual pues es aquello que les permite la expresión abierta de la identidad sexual y genérica por medio del establecimiento de redes de apoyo y soporte emocional con otras personas, inicialmente en espacios de vinculación como los lugares 'de ambiente', pasando también por los espacios de interacción y las redes sociales.

Esta conexión es la que, en primer lugar, fue identificada como alentadora para el proceso de 'salir del clóset' o asumir la identidad o definición como lesbiana ante los demás (amigos, familia, comunidad) y, como consecuencia, en la confianza para desenvolverse y hacer uso de los espacios públicos para la socialización, la articulación de pares y la formación de agrupaciones. 


\section{Referencias}

Alfarache, A. (2005). Identidades Lesbianas y Cultura Feminista, México: Plaza y Valdés.

Aruquipa, D.; Estenssoro, P. \& Vargas, P. (2012). Memorias Colectivas: Miradas a la Historia del Movimiento TLGB de Bolivia. La Paz: Conexión Fondo de Emancipación.

Ballivián, W. (1992). Migración y crecimiento urbano en Santa Cruz: Bolivia, 1950-1992. Repositorio. Recuperado de: https://repositorio.cepal.org/bitstream/handle/11362/21209/D17163.05_es.pdf?sequence $=1 \&$ isAllowed $=y$

Barrientos, J. \& Cárdenas, M. (2013). Homofobia y calidad de vida de gay y lesbianas: una mirada psicosocial. Revista Psykhe, 22(1), 3-14.

Boschetti, A. (2009). Breve interpretación de la lucha por la hegemonía en Bolivia. XII Jornadas Interescuelas/Departamentos de Historia. Departamento de Historia, Facultad de Humanidades y Centro Regional Universitario Bariloche.

Castañeda, M. (2001). La Experiencia Homosexual. México: Paidós.

Cornejo, Mendoza y Rojas (2008). El enfoque biográfico: trayectorias, desarrollos teóricos y perspectivas. Revista Psykhe, 15(1), 95-106.

Chávez Turello, A. (2019). Identidad lesbiana como un derecho. Proceso de construcción como historia de vida. En: Asociación Civil de Desarrollo Social y Promoción Cultural ADESPROC, $2{ }^{\circ}$ Congreso nacional de Sexualidades y Estudios de Género. Congreso llevado a cabo en La Paz, Bolivia.

Garay Cruz, L. M. (2018). Colectivos de diversidad sexual, redes sociodigitales y ciberactivismo como escenarios de visiblidad. En: II Congreso Internacional Move. net sobre Movimientos Sociales y TIC, p 92-108. Grupo Interdisciplinario de Estudios en Comunicación, Política y Cambio Social de la Universidad de Sevilla (COMPOLÍTICAS). Congreso llevado a cabo en Sevilla, España

Gobierno Municipal de Santa Cruz de la Sierra (2019). Distritos municipales. Jurisdicción Territorial del Municipio. Recuperado de: http://www.gmsantacruz.gob.bo/jurisdiccionterritorial/distritos-municipales.php Accedido el 1 de noviembre de 2019.

Guerra, L. (2011). Subjetividades lesbianas en los espacios no inscritos de la identidad. Revista Aisthesis, (50), 157-171. En: https://scielo.conicyt.cl/scielo.php?script=sci_arttext\&pid=S071871812011000200008 . Accedido el 20 de noviembre de 2019.

Hernández, R.; Fernández, C. y Baptista, P. (2016). Metodología de la Investigación, México: Mc Graw Hill 
Herrera, F. (2007). Construcción de la identidad lésbica en Santiago de Chile. Revista Universum 22. Pp.151-163. https://scielo.conicyt.cl/scielo.php?script=sci_arttext\&pid=S071823762007000200010. Accedido el 14 de enero de 2019

Instituto Nacional de Estadística (2016). Santa Cruz concentra la mayor población de Bolivia. Principales indicadores. Recuperado de: https://www.ine.gob.bo/index.php/principalesindicadores/item/418-santa-cruz-concentra-la-mayor-poblacion-de-bolivia. Accedido el 20 de octubre de 2019

Juliano, D. (2006). Lesbianismo y Roles de Género. Red Iberoamericana por las Libertades Laicas. En: http://www.rompiendoelsilencio.cl/artiene6.htm. Accedido el 25 de septiembre de 2018

Justiniano, D. (2011). Identidad urbana y élites cruceñas. Revista Aportes de la Comunicación y la Cultura, (37).

Lacombe, A. (2013). Sobre saias, calças e bonés: expressão de gênero, geração e sedução entre mulheres que "gostam de mulher". Antropolitica Revista Contemporanea de Antropologia, (34). DOI: https://doi.org/10.22409/antropolitica2013.0i34.a169

Le Garrec, E. (1989). Mujeres que se aman. Argentina: Ediciones de la Flor.

Makaran, G. (2017). La identidad camba. La Colmena, (65/66), 112-122. En: https://lacolmena.uaemex.mx/article/view/5819. Accedido el 17 de octubre de 2019.

Mayobre, P. (2001). Decir el mundo en femenino. En Identidad y Cultura. Simposio Internacional de Filosofía. La Coruña: Ed. Universidad de la Coruña - Servicio de Publicaciones.

Mejía, C. \& Pizarro, K. (2011). La construcción imaginaria del género con respecto a la homosexualidad En Mejía, C, Pizarro, K. \& Cabral, B. Estudios de género, feminismo y sexualidad Instituto de Ciencias Sociales y Humanidades. Universidad Autónoma del Estado de Hidalgo: Hidalgo: 17-48

Ministerio de Comunicación del Estado Plurinacional de Bolivia (2018) Comunicar para vivir con diversidad. Por un estado que respeta la diversidad sexual y la identidad de género. La Paz: Estado Plurinacional de Bolivia.

Mogrovejo, N. (2008). Diversidad sexual, un concepto problemático. Trabajo social UNAM, (18).

Peña Claros, C. \& Boschetti, A. (2008). Desafiar el mito camba-colla: interculturalidad, poder y resistencia en el Oriente boliviano. La Paz: Fundación UNIR.

Peña Claros, C. (2011). ¿Vos confiás? Capital social, identidad y desarrollo en Santa Cruz. La Paz: Fundación Friedrich Ebert. 
Peña Hasbún, P. (2003). La permanente construcción de lo cruceño: un estudio sobre la identidad en Santa Cruz de la Sierra. Santa Cruz de la Sierra: Fundación PIEB.

Platero, R. y Fernández, C. (s/f). Conceptos clave sobre homosexualidad y lesbianismo. Madrid: RQTR.

Prado Zanini, I. (2008). Sectores periurbanos en la Santa Cruz dual. Revista Tinkazos, 11(25), 7986.

Preciado, B. (2010). La sexualidad es como las lenguas. Todos podemos aprender varias. El País, 13 de junio de 2010.

https://elpais.com/diario/2010/06/13/eps/1276410414_850215.html_Accedido el 18 de octubre de 2019.

Puerta Sánchez, S. \& González Barea, E.M. (2015). Reproducción de los estereotipos de género en Educación Infantil a través de los juegos y juguetes. Revista de Investigación en la Escuela (85), 63-74.

Quiles, J. (2001). Más que amigas, Barcelona: Plaza y Janés Editores.

Rabbia, H. H., \& Iosa, T. A. (2011). Construcción de rutinas espaciales y sus efectos en las dinámicas de inclusión-exclusión del activismo LGBT de Córdoba, Argentina. Revista Sexualidad, Salud y Sociedad, (7), 103-126.

Rich, A. (2009). Heterosexualidad obligatoria y existencia lesbiana. Flor del Guanto. Revista Feminista(1), 52-55.

Roque Guerra, A. (2018). Sexualidades no heteronormativas, vulnerabilidades y ética de protección. Revista Sexología y Sociedad, 24(1). Recuperado de http://revsexologiaysociedad.sld.cu/index.php/sexologiaysociedad/article/view/642/668

Sanabria, C. (2016). Violencia contra las mujeres: entre avances y resistencias. Estudio en tres ciudades de Bolivia. Santa Cruz de la Sierra: Colectivo Rebeldía - OXFAM.

Sánchez, C., Gil, M., Farah, I., \& Tapia, L. (2016). La politización en la diferencia. Experiencias y diálogos políticos de las mujeres en Bolivia. La Paz: Instituto Sociedades en Transformación (ISET) - Conexión Fondo de Emancipación.

Sandoval, C. (2002). Investigación Cualitativa. Bogotá: Instituto Colombiano Para El Fomento de la Educación Superior (ICFES)

Sanfeliu, L. (2007). Escrito en el cuerpo. Sexualidades femeninas al margen de la norma heterosexual. Arenal. Revista de historia de las mujeres, 14(1), 31-57. Sciortino, M. S. (noviembre de 2012). La etnografía en la construcción de una perspectiva de género situada. Clepsydra(11), 41-58.

Sardà, A., Posa Guinea, R. M., \& Villalba Morales, V. (2006). Lesbianas en América Latina: de la inexistencia a la visibilidad. Aportes andinos, 15. http://hdl.handle.net/10644/798 
Silva Luévanos, B. E. (2018). Efectos en el afrontamiento y soporte social ante la revelación de la homosexualidad a la familia: estudio comparativo en gais y lesbianas. Psicogente, 21(40), 321336. https://doi.org/10.17081/psico.21.40.3077

Taylor, S. \& Bogdan, R. (1984). Introducción a los Métodos Cualitativos de Investigación, Madrid: Editorial Paidós.

Villarroel, A. (2018). Influencia de líderes de opinión en los imaginarios de jóvenes de Santa Cruz sobre la homosexualidad. Revista Aportes de la Comunicación y la Cultura, (25), 37-48. Recuperado de: http://www.scielo.org.bo/scielo.php?script=sci_arttext\&pid=S2306$86712018000200004 \& \operatorname{lng}=\mathrm{es} \& \operatorname{lng}=\mathrm{es}$ 